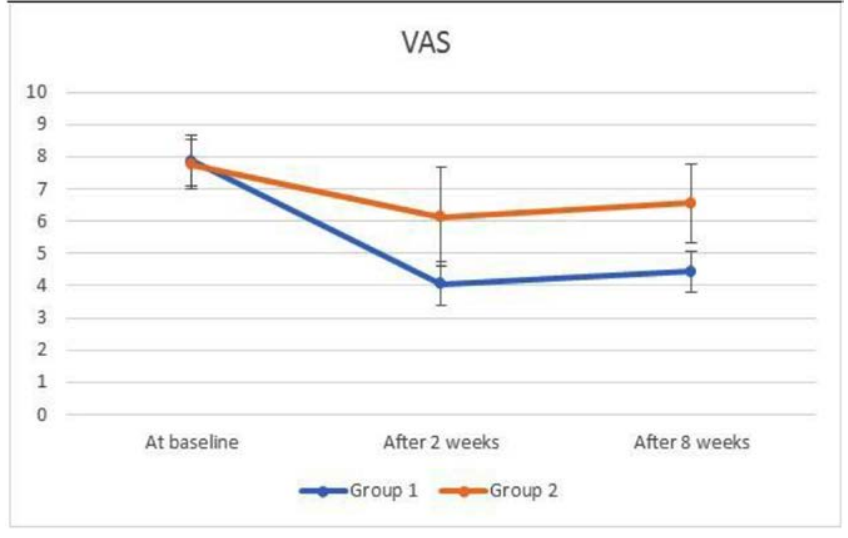

Figure 1. Change of VAS between the two groups.

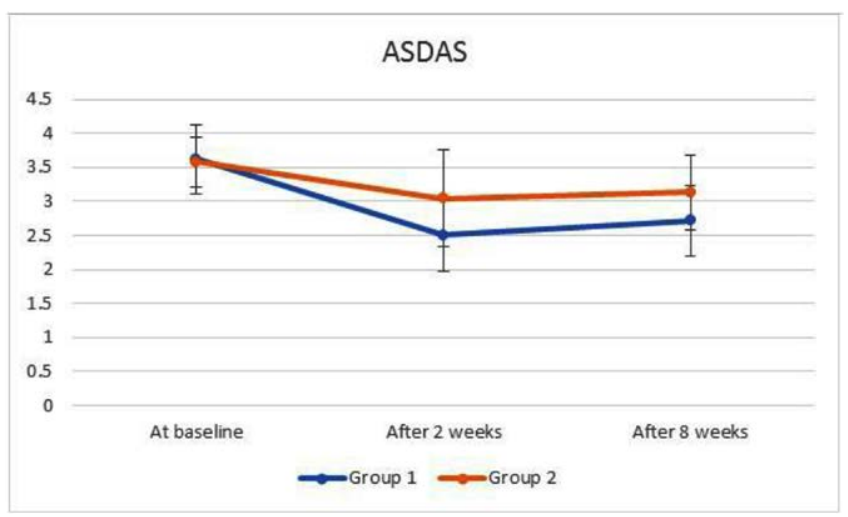

Figure 2. Change of VAS between the two groups.

Conclusion: Caudal epidural injection is cheap, effective and practical technique in controlling pain and stiffness of the spine in radiographic axial SPA with acceptable complications and relatively sustained effect. Studies including bigger number of participants and longer span of follow up still required.

Table. Comparison between the two groups as regards demographic and outcome data

\begin{tabular}{lcccc}
\hline Item & & Group 1 & Group 2 & P value \\
\hline Age & Male & $40.31 \pm 4.54$ & $38.88 \pm 5.44$ & 0.423 \\
Sex & Female & $10(62.5 \%)$ & $9(56.2 \%)$ & 0.719 \\
& (in years) & $3.13 .5 \%)$ & $7(43.8 \%)$ & \\
Disease duration & At baseline & $7.88 \pm 0.81$ & $3.22 \pm 1.24$ & 0.847 \\
VAS & After 2 weeks & $4.06 \pm 0.68$ & $6.13 \pm 0.77$ & 0.658 \\
& After 8 weeks & $4.44 \pm 0.63$ & $6.56 \pm 1.21$ & $<0.001$ \\
& \% improved at 2 weeks & $11(68.8 \%)$ & $3(18.8 \%)$ & $\mathbf{0 . 0 0 4}$ \\
& \% improved at 8 weeks & $6(37.5 \%)$ & $2(12.5 \%)$ & 0.102 \\
ASDAS & At baseline & $3.62 \pm 0.51$ & $3.58 \pm 0.37$ & 0.814 \\
& After 2 weeks & $2.50 \pm 0.53$ & $3.04 \pm 0.71$ & $\mathbf{0 . 0 2 0}$ \\
& After 8 weeks & $2.72 \pm 0.52$ & $3.13 \pm 0.55$ & $\mathbf{0 . 0 3 6}$ \\
& \% improved at 2 weeks & $10(62.5 \%)$ & $3(18.8 \%)$ & $\mathbf{0 . 0 1 2}$ \\
& \% improved at 8 weeks & $7(43.8 \%)$ & $2(12.5 \%)$ & 0.057 \\
\hline
\end{tabular}

Acknowledgments: None

Disclosure of Interests: None declared

DOI: 10.1136/annrheumdis-2020-eular.501

\section{AB0645 PREDICTORS OF THE EFFECTIVENESS OF INTRA- ARTICULAR GLUCOCORTICOID INJECTIONS IN RHEUMATIC HIP INVOLVEMENT}

H. Ferjani ${ }^{1}$, L. Ben Ammar ${ }^{1}$, K. Maatallah ${ }^{1}$, D. Ben Nessib ${ }^{1}$, D. Kaffel ${ }^{1}$, W. Hamdi'. 'Kassab Institute, Rheumatology, Tunis, Tunisia

Background: Hip involvement in chronic inflammatory rheumatic diseases is a turning point in the course of the disease because of disability and functional impairment. Total joint replacement surgery rate in spondyloarthritis increased
$40 \%$ despite the use of Disease-modifying anti-rheumatic drugs (DMARD) and biologic treatment. Intra-articular glucocorticoid injection may help prevent hip joint replacement surgery and radiographic progression.

Objectives: This study aimed to determine predictive factors of the steroid injections' efficiency in chronic inflammatory rheumatic diseases with hip involvement.

Methods: This is a retrospective study over a 13-years (2006-2019) that included patients followed for chronic inflammatory rheumatic diseases complicated by hip involvement and underwent intra-articular glucocorticoid injection.

Results: Forty-two patients were enrolled: 32 male $(76,2 \%)$ and 10 women $(23,8 \%)$. The average age was 27 years [6-73] at the time of the steroid injection. Ankylosing spondylitis (AS) was present in $73,8 \%$ of cases (radiographic axial spondylarthritis $90,3 \%$, Psoriatic spondylitis $6,5 \%$ and peripheral enthesitis $3.2 \%$ ) and juvenile idiopathic arthritis (JIA) in $26.2 \%$ of cases (enthesitis-related arthritis $63,6 \%$, oligoarticular JIA 18,2\%, seronegative polyarticular JIA 9,1\% and juvenile psoriatic arthritis $9,1 \%$ ). Active smoking was found in $47.6 \%$ of cases. All patients were on DMARD: NSAIDs (19\%), methotrexate $(42.9 \%)$, salazopyrin $(23.8 \%)$, combination of methotrexate and salazopyrin $(2.4 \%)$ and anti-TNF alpha $(7.1 \%)$.

Hip involvement was bilateral in $81 \%$ of patients. Examination revealed pain and limited hip mobility in all cases. Radiographic forms in AS were: early coxitis $(17,2 \%)$, condensing form $(17,2 \%)$, destructive form $(58,6 \%)$, synostosante $(3,4 \%)$ et combined $(3,4 \%)$. During JIA, hip involvement was destructive in $45.4 \%$ of cases and minimal to moderate in the remaining cases.

Lequesne algofunctional index averaged 11 (3-18). An improvement was reported in $63.4 \%$ of cases. Statistically significant decrease was found in the BASDAI score, visual analogue scale (VAS) for general health status as estimated by the patient and C-reactive Protein (CRP) $(p=0.001 ; p=0.01$ and $\mathrm{p}=0.03$; respectively).

There was no statistically significant difference between the efficacy of intra-articular glucocorticoid injection and sex, age, smoking, diagnosis and whether the hip involvement was bilateral or not $(p=0.5 ; p=0.2 ; p=0.8$ and $p=0.1 ; p=0.6$; respectively). Steroid injections were less effective in patients treated with biologics $(p=0.04)$. However, it was more effective in AS with early hip involvement $(\mathrm{p}=0.03)$.

Conclusion: Hip involvement is a negative prognostic factor in chronic inflammatory rheumatic diseases. Therefore, early diagnosis and management is essential in order to slow down the structural progression and the need for prosthetic surgery.

Disclosure of Interests: None declared

DOI: 10.1136/annrheumdis-2020-eular.6398

\section{AB0646 \\ IS IT FEASIBLE TO ACHIEVE RECOMMENDED THERAPEUTICAL TARGET IN PATIENTS WITH AXIAL SPONDYLARTHRITIS IN CLINICAL PRACTICE? DATA FROM THE SPA-PAZ COHORT}

K. N. Franco Gomez ${ }^{1}$, C. Plasencia', M. Novella-Navarro',

D. Benavent ${ }^{1}$, P. Bogas ${ }^{1}$, R. Nieto ${ }^{1}$, I. Monjo ${ }^{1}$, L. Nuño ${ }^{1}$, A. Villalva ${ }^{1}$,

D. Peiteado ${ }^{1}$, A. Balsa ${ }^{1}$, V. Navarro-Compán ${ }^{1} .{ }^{1}$ University Hospital La Paz,

Rheumatology, Madrid, Spain

Background: Current ASAS/EULAR recommendations for the management of patients with axial spondylarthritis (axSpA) establish that the therapeutic goal to achieve in clinical practice is remission, defined as the absence of both clinical and laboratory disease activity evaluated by BASDAI\&CRP or preferably ASDAS and if this is not possible, low disease activity may be an alternative. Recently, ASDAS nomenclature has been modified, calling now low disease activity to what was previously called moderate activity. To this day we do not know if this target is feasible in clinical practice.

Objectives: To analyze the frequency of patients with axSpA achieving maintained remission (R) or low disease activity (LDA) after receiving biological therapy. Secondary objectives included: i) to assess if the activity index used influences the frequency of maintained R/LDA, ii) analyze the prognostic factors for achieving maintained R/LDA.

Methods: An observational, longitudinal study of a prospective cohort (SpA$\mathrm{Paz}$ ) including all patients with axSpA who initiated their first biological treatment between the years 2003-2017. Demographic, clinical and analytical data were collected at the beginning of treatment and clinical disease activity measured by BASDAI\&CRP and ASDAS every 6 months for 2 years. Maintained R was defined as (BASDAl<2 \& normal CRP and/or ASDAS $<1.3$ ) and maintained LDA (BASDAI $<4$ \& normal CRP and/or ASDAS $<2.1$ ) on at least 3 consecutive visits. Statistical analysis: i) measures of central tendency and dispersion for quantitative variables and frequencies for qualitative variables; ii) univariate and multivariate analysis of binomial logistic regression model and calculation of $\mathrm{OR}$ and $95 \% \mathrm{Cl}$. 
Results: Out of 186 patients with axSpA who started treatment during the study period, $63 \%$ were men with a mean age of $54 \pm 14.1$ years. $75.3 \%$ of the patients had radiographic axSpA and $74.7 \%$ were HLA-B27 positive. Other baseline characteristics (not shown due to space restrictions). Overall, $80 \%$ of the patients achieved ASDAS R/LDA (R36\%/LDA44\%) in at least one of the visits after 2 years of follow-up, but only $40 \%$ (R27\%/LDA $13 \%$ ) fulfilled the maintained ASDAS R/LDA state. On the other hand, $73 \%$ of patients were classified as BASDAI\&CRP R/LDA (R31\%/LDA42\%) in at least one of the visits, but only $31 \%$ (R21\%/LDA $10 \%)$ obtained the maintained BASDAI\&CRP R/LDA state. In the multivariate analysis, we observed an independent statistically significant association with male sex (OR=3.19; $95 \% \mathrm{Cl}=1.46-6.99)$, younger age at the beginning of the biological treatment $(\mathrm{OR}=0.97 ; 95 \%$ $\mathrm{Cl}=0.95-0.99)$ and the use of methotrexate (OR=3.07; 95\% Cl=1.39-6.78) in patients who achieved maintained BASDAI\&CRP R/LDA and with male sex $(O R=4.01 ; 95 \% \quad C l=1.83-8.77)$, younger age at the beginning of the biological therapy $(\mathrm{OR}=0.96 ; 95 \% \mathrm{Cl}=0.94-0.99)$ and $\mathrm{HLA} \mathrm{B} 27$ presence $(\mathrm{OR}=4.30 ; 95 \% \mathrm{Cl}=1.68-11.01)$ in patients who achieved maintained ASDAS R/LDA.

Conclusion: Although the majority of patients with axSpA who initiate biological therapy achieve the recommended therapeutic goal in the first two years of treatment, the percentage of patients who manage to maintain the R/LDA status is limited. In our study, maintained $R$ was more frequent than maintained LDA, being somewhat higher when measured by ASDAS. This fact may suggest that patients who achieve maintained $\mathrm{R}$ have a greater inhibition of their inflammatory activity and, therefore, it remains in time. Male sex and younger age at the beginning of the biological therapy were the main baseline predictors for achieving maintained R/LDA.

\section{Graphics:}

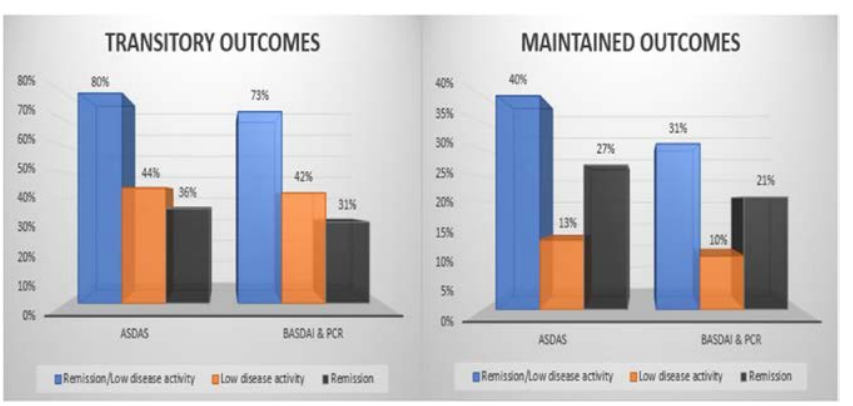

Disclosure of Interests: Karen Nathalie Franco Gomez: None declared, Chamaida Plasencia: None declared, Marta Novella-Navarro: None declared, Diego Benavent: None declared, Patricia Bogas: None declared, Romina Nieto: None declared, Irene Monjo: None declared, Laura Nuño: None declared, Alejandro Villalva: None declared, Diana Peiteado Grant/research support from: AbbVie, Lilly, MSD, and Roche, Speakers bureau: AbbVie, Roche, and MSD, Alejandro Balsa Grant/research support from: BMS, Roche, Consultant of: AbbVie, Gilead, Lilly, Pfizer, UCB, Sanofi, Sandoz, Speakers bureau: AbbVie, Lilly, Sanofi, Novartis, Pfizer, UCB, Roche, Nordic, Sandoz, Victoria Navarro-Compán Consultant of: Abbvie, Lilly, Novartis, Pfizer, UCB, Speakers bureau: AbbVie, MSD, Lilly, Novartis, Pfizer, UCB

DOI: 10.1136/annrheumdis-2020-eular.4617

\section{AB0647 1 THE EFFECT OF EXTRACORPOREAL SHOCK WAVE THERAPY (ESWT) ON PLANTAR FASCIITIS IN PATIENTS WITH AXIAL SPONDYLOARTHROPATHIES: DOUBLE-BLIND, RANDOMIZED CONTROLLED TRIAL}

S. Güneş ${ }^{1}$, Ö. C. Caner ${ }^{1}$, D. Gökmen ${ }^{2}$, Ş. Ataman ${ }^{3}$, Ş. Kutlay ${ }^{1} .{ }^{1}$ Ankara University School of Medicine, Physical Medicine and Rehabilitation, Ankara, Turkey; ${ }^{2}$ Ankara University School of Medicine, Biostatistics, Ankara, Turkey; ${ }^{3}$ Ankara University School of Medicine, Physical Medicine and Rehabilitation, Rheumatology, Ankara, Turkey

Background: The effectiveness and safety of radial extracorporeal shock wave therapy ( $r$-ESWT) on chronic plantar fasciitis (PF) in patients with axial spondyloarthropathies $(\mathrm{SpA})$ remains unclear.

Objectives: To investigate the efficacy and tolerability of r-ESWT in patients with $\mathrm{PF}$ in axial-SpA on the clinical and radiological parameters

Methods: In this double-blind, randomized controlled trial, 22 axial-SpA patients with PF whom have heel pain above 5 according to Visual Analog
Scale (VAS) over 3 months were randomly divided into two groups: r-ESWT (1.8 bar pressure, 10 Hertz frequency, 500 pulse intensity) and sham ESWT. Both groups received a total of 3 treatments at one week intervals. All patients were assessed by using the VAS, heel pressure algometry, Foot Function Index and plantar fascia ultrasonography (thickness, convexity, echogenicity of PF presence of perifascial fluid and subcutaneous tissue edema) at baseline, one week after each session and $4^{\text {th }}$ and $8^{\text {th }}$ week after the last therapy. $A$ decrease of more than two units on the VAS and improvements on plantar fascia ultrasonographic assessments was considered as primary and secondary endpoints respectively.

Results: Descriptive data of the patients are presented in table 1. Both groups showed significant improvements in all assessment parameters $(p<0.05)$ after the therapy sessions and at the $4^{\text {th }}$ and $8^{\text {th }}$ week follow-up. No serious adverse event was observed in any patient. When two groups were compared regarding the differences in improvements, no statistically significant difference was found between the r-ESWT and sham ESWT groups in any of the parameters $(p>0.05)$.

Table 1. Baseline demographic characteristics of patients

\begin{tabular}{|c|c|c|}
\hline & $r$-ESWT group $(n: 10)$ & Sham group (n:12) \\
\hline \multicolumn{3}{|l|}{$\operatorname{Sex}(n, \%)$} \\
\hline Female & $7(\% 70)$ & $9(\% 75)$ \\
\hline $\mathrm{Age}^{\star}$ (year) & $43.8 \pm 8.23$ & $48.5 \pm 7.62$ \\
\hline Height $^{\star}(\mathrm{cm})$ & $163.1 \pm 7.17$ & $160.75 \pm 11.71$ \\
\hline Weight * ${ }^{*}(\mathrm{~kg})$ & $80.1 \pm 9.38$ & $81.67 \pm 22.31$ \\
\hline $\mathrm{BMI}^{*}\left(\mathrm{~kg} / \mathrm{cm}^{2}\right)$ & $30.2 \pm 3.92$ & $31.11 \pm 5.42$ \\
\hline \multicolumn{3}{|l|}{ Duration of heel pain $n,(\%)$} \\
\hline$>6$ month & $8(\% 80)$ & $10(\% 83.3)$ \\
\hline 3-6 month & $2(\% 20)$ & $2(\% 16.7)$ \\
\hline VAS $(0-10)$ & $8.22 \pm 1.394$ & $7.82 \pm 0.603$ \\
\hline FFI scores* & Right Left & Right Left \\
\hline Pain & $60.66 \pm 22.2051 .11 \pm 33.37$ & $61.18 \pm 21.5563 .18 \pm 9.83$ \\
\hline Disability & $66.66 \pm 16.3451 .55 \pm 34.20$ & $68.09 \pm 27.2372 .27 \pm 18.74$ \\
\hline & $60.33 \pm 31.35$ & \\
\hline Activity restriction & $44.77 \pm 41.08$ & $\begin{array}{c}58.72 \pm 35.51 \\
62.36 \pm 29.28\end{array}$ \\
\hline Total & $62.66 \pm 15.0649 .14 \pm 31.60$ & $62.54 \pm 25.05$ \\
\hline Pressure algometry $\left(\mathrm{kg} / \mathrm{cm}^{2}\right)$ & $\begin{array}{c}\text { Right Left } \\
2.07 \pm 1.583 .86 \pm 4.09\end{array}$ & $\begin{aligned} & 65.90 \pm 15.89 \\
& \text { Right Left } \\
3.70 \pm & 3.173 .60 \pm 3.23\end{aligned}$ \\
\hline US measurements* & Right Left & Right Left \\
\hline PF thickness (mm) & $3.60 \pm 0.733 .40 \pm 0.71$ & $4.15 \pm 1.074 .04 \pm 1.12$ \\
\hline Increased PF convexity n (\%) & $4(40) 2(20)$ & 4 (33.3) 5 (41.7) \\
\hline Decreased echogenicity $n(\%)$ & $2(20) 3(30)$ & $6(50) 8(66.7)$ \\
\hline Perifascial fluid (+) n (\%) & $2(20) 0(0)$ & $3(25) 4$ (33.3) \\
\hline Subcutaneus tissue edema (+) $n(\%)$ & $8(80) 6(60)$ & $8(66.7) 9(75)$ \\
\hline
\end{tabular}

Conclusion: To the best of our knowledge, this is the first study evaluating the clinical and radiological efficacy and tolerability of $r$-ESWT in patients with PF in axial-SpA. Radial extracorporeal shock wave therapy is safe and tolerable treatment on chronic PF in patients with axial-SpA.

References:

[1] Dizon JN, Gonzalez-Suarez C, Zamora MT, Gambito ED. Effectiveness of extracorporeal shock wave therapy in chronic plantar fasciitis: a meta-analysis. Am J Phys Med Rehabil. 2013 Jul;92(7):606-20

Acknowledgments: None

Disclosure of Interests: None declared

DOI: 10.1136/annrheumdis-2020-eular.4433

\section{AB0648 COMPARING SYMPTOMS, TREATMENT PATTERNS, AND QUALITY OF LIFE OF ANKYLOSING SPONDYLITIS PATIENTS AND NON-RADIOGRAPHIC AXIAL SPONDYLOARTHRITIS IN JAPAN}

T. Tomita ${ }^{1}$, T. Aranishi ${ }^{2}$, K. Hagimori ${ }^{2}$, K. Nakajo ${ }^{2}$, N. Booth ${ }^{3}$, E. Holdsworth ${ }^{3}$, T. Hunter ${ }^{4} .{ }^{1}$ Osaka University, Osaka, Japan; ${ }^{2}$ Lilly, Kobe, Japan; ${ }^{3}$ Adelphi, Folkestone, United Kingdom; ${ }^{4}$ Lilly, Indianapolis, United States of America

Background: Axial spondyloarthritis (axSpA) is a chronic inflammatory disease of the axial skeleton associated with impaired health-related quality of life (QoL) and disability.

Objectives: To better understand the symptoms, clinical characteristics, treatment patterns, and quality of life (QoL), of non-radiographic axial spondyloarthritis (nr-axSpA) patients and how they compare to ankylosing spondylitis (AS) patients in Japan.

Methods: Data from a cross-sectional survey conducted with physician (rheumatologists, orthopedic surgeon, and internal medicine) and their consulting 